\title{
Cornichons Modify Channel Properties of Recombinant and Glial AMPA Receptors
}

\author{
Ian D. Coombs, ${ }^{\star}$ David Soto, ${ }^{\star}$ Marzieh Zonouzi, ${ }^{\star}$ Massimiliano Renzi, Chris Shelley, Mark Farrant, \\ and Stuart G. Cull-Candy \\ Department of Neuroscience, Physiology and Pharmacology, University College London, London WC1E 6BT, United Kingdom
}

\begin{abstract}
Ionotropic glutamate receptors, which underlie a majority of excitatory synaptic transmission in the CNS, associate with transmembrane proteins that modify their intracellular trafficking and channel gating. Significant advances have been made in our understanding of AMPA-type glutamate receptor (AMPAR) regulation by transmembrane AMPAR regulatory proteins. Less is known about the functional influence of cornichons - unrelated AMPAR-interacting proteins, identified by proteomic analysis. Here we confirm that cornichon homologs 2 and 3 (CNIH-2 and CNIH-3), but not CNIH-1, slow the deactivation and desensitization of both GluA2-containing calciumimpermeable and GluA2-lacking calcium-permeable (CP) AMPARs expressed in tsA201 cells. CNIH-2 and -3 also enhanced the glutamate sensitivity, single-channel conductance, and calcium permeability of CP-AMPARs while decreasing their block by intracellular polyamines. We examined the potential effects of CNIHs on native AMPARs by recording from rat optic nerve oligodendrocyte precursor cells (OPCs), known to express a significant population of CP-AMPARs. These glial cells exhibited surface labeling with an anti-CNIH-2/3 antibody. Two features of their AMPAR-mediated currents-the relative efficacy of the partial agonist kainate $\left(I_{\mathrm{KA}} / I_{\mathrm{Glu}}\right.$ ratio 0.4$)$ and a greater than fivefold potentiation of kainate responses by cyclothiazide—-suggest AMPAR association with CNIHs. Additionally, overexpression of CNIH-3 in OPCs markedly slowed AMPAR desensitization. Together, our experiments support the view that CNIHs are capable of altering key properties of AMPARs and suggest that they may do so in glia.
\end{abstract}

\section{Introduction}

Throughout the CNS, AMPARs mediate rapid excitatory signaling between neurons and between neurons and glia. AMPARs are homotetrameric or heterotetrameric assemblies of the pore-forming subunits GluA1-4, whose properties depend critically on their subunit composition and on the nature of alternatively spliced or posttranscriptionally edited variants (Traynelis et al., 2010). The GluA2 subunit is particularly important, as editing at its $\mathrm{Q} / \mathrm{R}$ site in the pore profoundly affects calcium permeability of the receptors. Thus, AMPARs lacking GluA2 are permeable to calcium (Geiger et al., 1995), have a large single-channel conductance (Swanson et al., 1997), and

Received Jan. 24, 2012; revised April 20, 2012; accepted May 18, 2012.

Author contributions: M.F. and S.G.C.-C. designed research; I.D.C., D.S., M.Z., M.R., and C.S. performed research; I.D.C., D.S., M.Z., M.R., C.S., and M.F. analyzed data; I.D.C., M.F., and S.G.C.-C. wrote the paper.

The authors declare no competing financial interests.

This work was supported by programme grants from the Wellcome Trust and the Medical Research Council (S.G.C.-C., M.F.). Cornichon cDNAs and antibody to CNIH-2/3 were gifts from Bernd Fakler (University of Freiburg, Freiburg, Germany), and TARP cDNAs were gifts from Roger Nicoll (University of California, San Francisco, San Francisco, CA). M.Z. was supported by the Medical Research Council studentship programme of the Laboratory of Molecular Cell Biology, University College London. We thank Cécile Bats and Dorota Studniarczyk for discussion.

*I.D.C., D.S., and M.Z. contributed equally to this work.

Correspondence should be addressed to either Mark Farrant or Stuart G. Cull-Candy, Department of Neuroscience, Physiology and Pharmacology, University College London, Gower Street, London WC1E 6BT, United Kingdom. E-mail:m.farrant@ucl.ac.uk or s.cull-candy@ucl.ac.uk.

D. Soto's present address: Laboratori de Neurobiologia-IDIBELL, Feixa LLarga s/n, 08907 L'Hospitalet de Llobregat, Barcelona, Spain.

M. Renzi's present address: Dipartimento di Fisiologia e Farmacologia, Sapienza Universita di Roma, P.le A. Moro 5, I-00185, Rome, Italy.

DOI:10.1523/JNEUROSCI.0345-12.2012

Copyright $\odot 2012$ the authors $\quad 0270-6474 / 12 / 329796-09 \$ 15.00 / 0$ exhibit characteristic voltage-dependent block by endogenous intracellular polyamines (Bowie and Mayer, 1995; Kamboj et al., 1995; Koh et al., 1995).

The properties of both calcium-impermeable (CI) and calciumpermeable $(\mathrm{CP})$ AMPARs are strongly influenced by their interaction with transmembrane AMPAR regulatory proteins (TARPs). Six TARP isoforms have been identified- $\gamma$-2 (stargazin), $\gamma-3, \gamma-4, \gamma-5$, $\gamma-7$, and $\gamma-8$-that differentially modulate the trafficking, gating, and pharmacology of AMPARs (Tomita et al., 2003; Fukaya et al., 2005; Cho et al., 2007; Milstein et al., 2007; Soto et al., 2007, 2009; Kato et al., 2008, 2010a). Recently, cornichon homologs 2 and 3 (CNIH-2 and CNIH-3) were identified by proteomic analysis as AMPAR-interacting proteins and were suggested to form part of the AMPAR assembly at the cell surface of various neurons and glia (Schwenk et al., 2009). Coexpression of recombinant AMPARs with CNIH proteins, as with TARPs, increases the surface expression of receptors and slows their deactivation and desensitization (Schwenk et al., 2009; Kato et al., 2010b; Shi et al., 2010; Gill et al., 2011). However, the status of CNIHs as bona fide AMPAR auxiliary subunits has been the subject of debate (Jackson and Nicoll, 2009, 2011; Tigaret and Choquet, 2009; Brockie and Maricq, 2010; Shi et al., 2010).

Here we have compared the effects of CNIH-1, CNIH-2, and CNIH-3 with those of stargazin (TARP $\gamma$-2) on both GluA2lacking CP-AMPARs and GluA2-containing CI-AMPARs. We found that $\mathrm{CNIH}-2$ and -3 markedly increased single-channel conductance of CP-AMPARs and slowed the desensitization and deactivation of both CI- and CP-AMPARs. Furthermore, in the presence of $\mathrm{CNIH}-2$ or -3 , CP-AMPARs displayed increased 
a

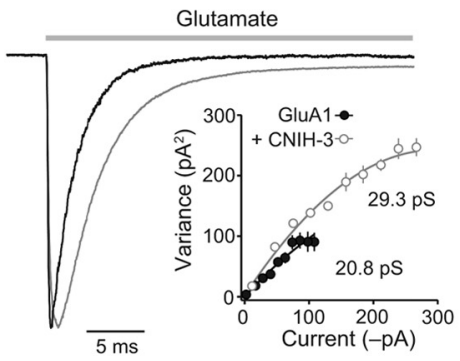

b
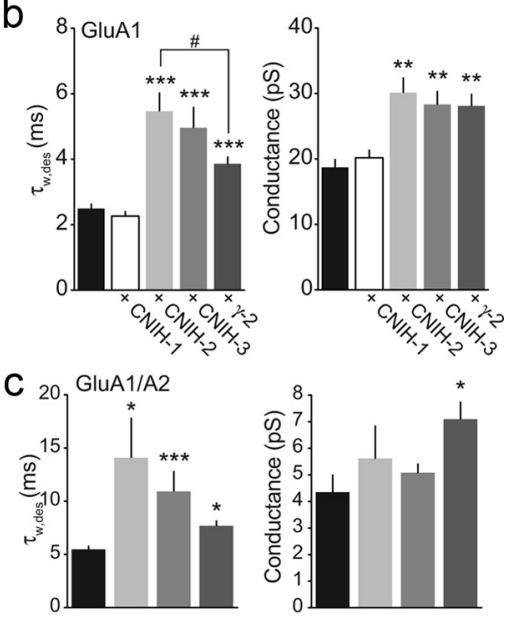

d GluA2(Q) \#\#
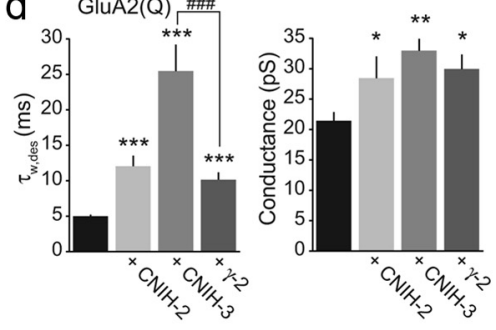

e

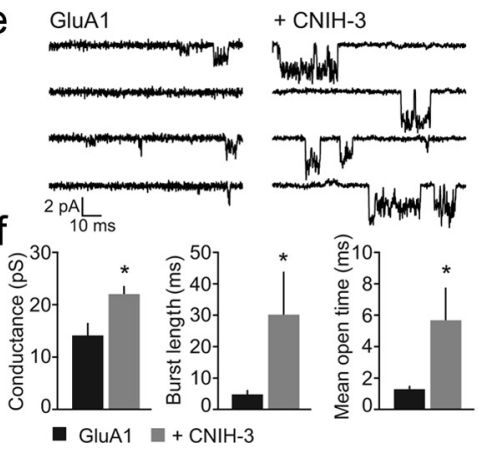

Figure 1. CNIHs modify single-channel conductance and desensitization of calciumpermeable AMPARs. $\boldsymbol{a}$, Peak-scaled currents activated by rapid application of $10 \mathrm{~mm}$ glutamate (100 ms, $-60 \mathrm{mV}$ ) to outside-out patches from tsA201 cells expressing GluA1 alone (black trace, average of 28 responses) or GluA1 coexpressed with CNIH-3 (gray trace, 89 responses). Inset, Corresponding plots of current variance versus mean current with weighted mean singlechannel conductance estimates. $\boldsymbol{b}$ - $\boldsymbol{d}$, Pooled data for GluA1 homomers, GluA1/A2 heteromers, and GluA2 (Q) homomers, comparing the effect of $\mathrm{CNIH}$ and $\gamma$-2 on the weighted time constant of desensitization ( $\tau_{\mathrm{w} \text {, des }}$ ) and the weighted mean single-channel conductance estimated from NSFA ( $n=6-25$; see Table 1 and Table 2). Bars show mean values, and error bars denote SEM. ${ }^{*} p<0.05,{ }^{* *} p<0.01$, versus control; ${ }^{\#} p<0.05,{ }^{\# \# \#} p<0.001$ versus $\gamma$-2.e, Representative single-channel currents recorded in outside-out patches from tsA201 cells with GluA1 expressed either alone or together with (NIH-3 ( $-80 \mathrm{mV} ; 10 \mathrm{~mm}$ glutamate). $f$, Pooled data ( $n=$ 5 and 7) showing increased chord conductance, mean burst duration, and mean open time $\left({ }^{*} p<0.05\right.$ versus GluA1 alone).
Table 1. Kinetic properties of homomeric GluA1 and GluA2(Q) receptors and heteromeric GluA1/A2(R) receptors coexpressed with CNIH-1, CNIH-2, CNIH-3, or $\gamma-2$

\begin{tabular}{cccc}
\hline & $\begin{array}{l}\text { Deactivation } \\
\left(\tau_{\mathrm{w}, \text { deact }}, \mathrm{ms}\right)\end{array}$ & $\begin{array}{l}\text { Desensitization } \\
\left(\tau_{\mathrm{w}, \text { des }}, \mathrm{ms}\right)\end{array}$ & $\begin{array}{l}\text { Steady-state } \\
\text { current }(\% \text { peak })\end{array}$ \\
\hline GluA1 & $1.3 \pm 0.2(10)$ & $2.6 \pm 0.1(22)$ & $1.9 \pm 0.3(22)$ \\
+ CNIH-1 & $1.0 \pm 0.2(6)^{\#}$ & $2.3 \pm 0.1(6)$ & $1.9 \pm 1.1(6)$ \\
+ CNIH-2 & $4.0 \pm 0.8(10)^{*}$ & $5.5 \pm 0.6(15)^{* * *, \#}$ & $6.7 \pm 2.3(15)$ \\
+ CNIH-3 & $3.3 \pm 0.6(14)^{*}$ & $5.0 \pm 0.6(10)^{* * *}$ & $4.1 \pm 1.4(10)$ \\
$+\gamma-2$ & $2.1 \pm 0.2(11)^{*}$ & $3.9 \pm 0.2(20)^{* * *}$ & $3.6 \pm 0.5(20)^{*}$ \\
GluA1/A2(R) & $0.8 \pm 0.1(5)$ & $5.5 \pm 0.3(13)$ & $3.8 \pm 0.7(13)$ \\
+ CNIH-2 & - & $14.1 \pm 3.7(6)^{*}$ & $15.2 \pm 5.2(6)^{* *}$ \\
+ CNIH-3 & $1.3 \pm 0.1(10)^{* *}$ & $10.9 \pm 1.9(10)^{* * *}$ & $13.2 \pm 3.2(10)^{* *}$ \\
$+\gamma-2$ & - & $7.7 \pm 0.5(12)^{*}$ & $20.4 \pm 2.4(12)^{* * *}$ \\
GluA2(Q) & $1.0 \pm 0.2(11)$ & $5.0 \pm 0.2(25)$ & $1.8 \pm 0.2(25)$ \\
+ CNIH-2 & - & $12.1 \pm 1.4(9)^{* * *}$ & $8.9 \pm 2.4(9)^{*}$ \\
+ CNIH-3 & $12.3 \pm 4.5(6)^{* *}$ & $25.5 \pm 3.7(12)^{* * *, \# \#}$ & $11.3 \pm 2.4(12)^{* * *}$ \\
$+\gamma-2$ & - & $10.2 \pm 1.0(12)^{* * *}$ & $6.7 \pm 1.5(12)^{* *}$ \\
\hline
\end{tabular}

Values are mean \pm SEM $(n)$. Tests of differences among group data were performed using a Kruskal-Wallis ranksum test followed by pairwise Wilcoxon rank-sum tests with Holm's sequential Bonferroni correction. Statistical significance of single comparisons [GluA2(Q) and GluA1/A2 deactivation] was determined using a Wilcoxon ranksum test. ${ }^{*} p<0.05,{ }^{* *} p<0.01,{ }^{* * *} p<0.001$ compared with AMPAR alone. ${ }^{\#} p<0.05,{ }^{\# \#} p<0.001$ compared with $+\gamma$ - 2 condition.

calcium permeability, decreased block by intracellular polyamines, and enhanced glutamate potency. Thus, for recombinant CP-AMPARs, interaction with CNIHs would be expected to facilitate AMPAR-mediated calcium entry. We examined the potential interaction of CNIHs and native CP-AMPARs in rat optic nerve oligodendrocyte precursor cells (OPCs), glial cells known to express CP-AMPARs (Bergles et al., 2000). OPCs exhibited surface immunolabeling with an antibody to $\mathrm{CNIH}-2 / 3$, consistent with the presence of cornichon proteins in the cell membrane. In whole-cell recordings from OPCs, the relative amplitude of responses elicited by glutamate and the partial agonist kainate, together with the marked potentiation of kainate responses by the positive allosteric modulator cyclothiazide (CTZ), also suggested the incorporation of CNIHs in functional surface AMPARs. Additionally, the overexpression of CNIH-3 in OPCs markedly slowed AMPAR desensitization. Our data suggest that the presence of CNIHs can influence key properties of AMPARs and that they may serve this function in OPCs.

\section{Materials and Methods}

Cell culture. tsA201 cells were maintained as described previously (Soto et al., 2007) and transfected using Lipofectamine 2000 (Invitrogen). DNA for GluA1(i) or GluA2(i)(Q), or both GluA1(i) and GluA2(i)(R), was transfected either alone or with CNIH-1, CNIH-2, CNIH-3, or $\gamma-2$. Coexpression of GFP was used to identify transfected cells. After $24 \mathrm{~h}$, cells were transferred to coverslips, and electrophysiological recordings were made 24-72 $\mathrm{h}$ later. Some transfections were maintained in the presence of $50 \mu \mathrm{M}$ NBQX to limit cytotoxic effects.

Electrophysiology. Solutions and procedures were as described previously (Soto et al., 2007). For outside-out patch and whole-cell recording, the "external" solution contained the following (in $\mathrm{mm}$ ): $145 \mathrm{NaCl}, 2.5$ $\mathrm{KCl}, 1 \mathrm{CaCl}_{2}, 1 \mathrm{MgCl}_{2}, 10$ glucose, and 10 HEPES, pH 7.3, with $\mathrm{NaOH}$. For fast application experiments, glutamate was used at a concentration of $10 \mathrm{~mm}$ [nonstationary fluctuation analysis (NSFA) and $I-V$ measurements] or $1 \mathrm{~mm}$ (measurement of deactivation). Jump experiments were performed at $-60 \mathrm{mV}$. Steady state single-channel recordings were performed in $10 \mathrm{~mm}$ glutamate at $-80 \mathrm{mV}$. The "internal" (pipette) solution contained the following (in $\mathrm{mm}$ ): $145 \mathrm{CsCl}, 2.5 \mathrm{NaCl}$, 1 Cs-EGTA, 4 MgATP, 0.1 spermine tetrahydrochloride, and 10 HEPES, pH 7.3, with $\mathrm{CsOH}$. Rapid solution switching was achieved by piezoelectric translation of a theta-barrel application tool. Fast exchange (10-90\% rise time $<200 \mu$ s) was confirmed by averaging liquid junction currents at the end of each experiment for both 1 and $100 \mathrm{~ms}$ steps. Measurement of relative 
Table 2. Conduction and rectification properties of homomeric GluA1 and GluA2(Q) receptors and heteromeric GluA1/A2(R) receptors coexpressed with CNIH-1, CNIH-2, CNIH-3, or $\gamma-2$

\begin{tabular}{|c|c|c|c|c|}
\hline & Conductance (pS) & $P_{0, \text { peak }}$ & $\mathrm{RI}_{+60 \backslash-80 \mathrm{mV}}$ & $-V_{112}(\mathrm{mV})$ \\
\hline GluA1 & $18.7 \pm 1.2(16)$ & $0.41 \pm 0.04(16)$ & $0.03 \pm 0.01(24)$ & $67.0 \pm 3.0(8)$ \\
\hline+ CNIH-1 & $20.2 \pm 1.2(6)$ & $0.26 \pm 0.08(6)$ & 一 & - \\
\hline$+\mathrm{CNIH}-2$ & $30.2 \pm 2.3(15)^{* *}$ & $0.46 \pm 0.05(15)$ & $0.07 \pm 0.01(17)^{* *, \# \#}$ & $54.0 \pm 2.8(7)^{* *, \# \#}$ \\
\hline$+\mathrm{CNIH}-3$ & $28.4 \pm 2.0(10)^{* * *}$ & $0.58 \pm 0.06(10)$ & $0.07 \pm 0.01(10)^{* *, \# \#}$ & $50.9 \pm 1.9(10)^{* *, \# \#}$ \\
\hline$+\gamma-2$ & $28.2 \pm 1.8(8)^{* *}$ & $0.64 \pm 0.06(8)^{*}$ & $0.17 \pm 0.01(6)^{* *}$ & $33.1 \pm 2.2(6)^{* *}$ \\
\hline GluA1/A2(R) & $4.4 \pm 0.6(13)$ & $0.40 \pm 0.06(13)$ & - & - \\
\hline$+\mathrm{CNIH}-2$ & $5.6 \pm 1.2(6)$ & $0.31 \pm 0.10(6)$ & - & - \\
\hline$+\mathrm{CNIH}-3$ & $5.1 \pm 0.3(8)$ & $0.36 \pm 0.07(8)$ & - & - \\
\hline$+\gamma-2$ & $7.1 \pm 0.6(9)^{*}$ & $0.58 \pm 0.03(9)$ & - & - \\
\hline GluA2(Q) & $21.6 \pm 1.5(23)$ & $0.45 \pm 0.04(25)$ & $0.08 \pm 0.03(11)$ & $61.5 \pm 1.3(7)$ \\
\hline+ CNIH-2 & $28.5 \pm 3.5(6)^{*}$ & $0.48 \pm 0.08(6)^{\#}$ & - & - \\
\hline$+\mathrm{CNIH}-3$ & $33.0 \pm 1.9(11)^{* *}$ & $0.61 \pm 0.05(11)$ & $0.17 \pm 0.04(5)^{*}$ & $46.5 \pm 5.8(4)^{*}$ \\
\hline$+\gamma-2$ & $29.5 \pm 3.2(6)^{*}$ & $0.71 \pm 0.03(12)^{*}$ & - & - \\
\hline
\end{tabular}

Values are mean \pm SEM $(n)$. Tests of differences among group data were performed using a Kruskal-Wallis rank-sum test followed by pairwise Wilcoxon rank-sum tests with Holm's sequential Bonferroni correction. Statistical significance of $\mathrm{CNIH}-3$ effect on GluA2 (Q) $V_{122}$ was determined using a Wilcoxon rank-sum test. ${ }^{*} p<0.05,{ }^{* *} p<0.01,{ }^{* * *} p<0.001$ compared with AMPAR alone. ${ }^{\#} p<0.05$, ${ }^{\# \#} p<0.01$ compared with $+\gamma$-2 condition.

calcium permeability was carried out as described previously (Soto et al., 2007). Ramps from -80 to $+60 \mathrm{mV}$ were applied in "low" and "high" $\mathrm{Ca}^{2+}$ solutions as follows (in mM): low Ca ${ }^{2+}: 145 \mathrm{NaCl}, 2.5 \mathrm{KCl}, 1 \mathrm{CaCl}_{2}$, $1 \mathrm{MgCl}_{2}, 10$ HEPES, pH 7.3, with $\mathrm{NaOH}$; high $\mathrm{Ca}^{2+}: 30 \mathrm{CaCl}_{2}, 110$ $\mathrm{N}$-methyl-D-glucamine, 5 HEPES, 50 sucrose, $\mathrm{pH} 7.3$, with $\mathrm{HCl}$. Control ramps were recorded in each $\mathrm{Ca}^{2+}$ solution, then in the same solutions containing $1 \mathrm{~mm}$ glutamate and $50 \mu \mathrm{M} \mathrm{CTZ}$ (Tocris Bioscience). Further control ramps were recorded on return to low $\mathrm{Ca}^{2+}$. The $I-V$ relationships of control ramps were subtracted from the agonist-evoked currents. In these experiments, the pipette solution contained either $100 \mu \mathrm{M}$ or no added spermine. As no differences in the reversal potentials were observed, the data were pooled. The relative $\mathrm{Ca}^{2+}$ permeability, $P_{\mathrm{Ca}} / P_{\mathrm{Na}}$, was determined from the reversal potentials in low $\mathrm{Ca}^{2+}$ and in high $\mathrm{Ca}^{2+}$ extracellular solutions using the equation

$$
P_{\mathrm{Ca}} / P_{\mathrm{Na}}=\frac{a_{\mathrm{Na}}}{4 a_{\mathrm{Ca}}}\left(\exp \frac{\left(2 V_{\mathrm{revCa}}-V_{\text {revNa }}\right) F}{R T}+\exp \frac{\left(V_{\text {revCa }}-V_{\text {revNa }}\right) F}{R T}\right)
$$

where $a_{\mathrm{Na}}$ and $a_{\mathrm{Ca}}$ represent the activities of $\mathrm{Na}^{+}$and $\mathrm{Ca}^{2+}$ in the extracellular solutions ( 108.7 and 16.5, calculated from activity coefficients of 0.75 and 0.55 , respectively) (Geiger et al., 1995), and $R, T$, and $F$ have their conventional meanings. Recording pipettes were pulled from borosilicate glass capillaries (Harvard Apparatus) coated with Sylgard 184 resin (Dow Corning) and fire polished to a final pipette resistance of 4-7 $\mathrm{M} \Omega$ (whole-cell recording) and 10-15 M $\Omega$ (outside-out patches). Pipettes contained standard "intracellular solution" (Soto et al., 2007) supplemented with $100 \mu \mathrm{M}$ spermine. For whole-cell recordings, series resistance was maintained between 5 and $16 \mathrm{M} \Omega$ and was compensated by 75\% (Axopatch 200A). Residual series resistance errors were corrected offline. Whole-cell input capacitances were $9-18 \mathrm{pF}$. Voltage ramps were performed every $5 \mathrm{~s}$ between $-70 \mathrm{mV}$ and $+60 \mathrm{mV}(100 \mathrm{mV} / \mathrm{s})$ following a 500 $\mathrm{ms}$ hold at $-70 \mathrm{mV}$. The average current for the $-70 \mathrm{mV}$ period was used to generate the steady state dose-response curves (CTZ was not used). Currents were filtered at $1 \mathrm{kHz}$ and sampled at $2 \mathrm{kHz}$. Records from outside-out patches were filtered at $10 \mathrm{kHz}$ and sampled at $50 \mathrm{kHz}$.

Data analysis. NSFA and Boltzmann fitting were carried out as described previously (Soto et al., 2007). $\mathrm{EC}_{50}$ values (peak or steady state) were derived by fitting the Hill equation:

$$
I=\frac{I_{\max }}{1+\left(\frac{\mathrm{EC}_{50}}{[\mathrm{Glu}]}\right)^{n_{\mathrm{H}}}}
$$

where $I_{\max }$ is the peak of the fit, $\mathrm{EC}_{50}$ is the concentration producing the half-maximal response and $n_{\mathrm{H}}$ is the Hill coefficient. $I_{\max }$ values derived from fits to individual experiments were used to rescale each dataset. The rescaled values were then averaged and refit for each receptor combination. The final fits were weighted according to the SD of the averages.
Single-channel records were filtered off-line at $2 \mathrm{kHz}$ (8-pole low-pass digital Clampfit 10, Bessel) before analysis and idealized using a 50\% threshold method (Clampfit 10, Bessel). Events briefer than two filter rise times were excluded from the analysis. To estimate the channel chord conductance, current amplitude histograms were constructed and fitted to the sum of Gaussian components. Open time histograms were fitted with mixtures of exponential functions to obtain mean open times. Bursts were defined as openings or groups of openings separated from each other by shut times greater than a critical shut time $\left(t_{\text {crit }}\right)$. These values were calculated as the lowest frequency shut time bin (10 bins/ decade) that clearly separated the "brief" shut time component from the "long" shut time component in the Sigworth-Sine transformed shut time distributions. Using this criterion, $t_{\text {crit }}$ values were consistently 8 to $10 \mathrm{~ms}$ for all patches. Mean burst duration and number of bursts were estimated using Scilab 5.2 (www.scilab.org).

OPC cultures. Optic nerve OPCs were prepared using the method of Shi et al. (1998). Briefly, optic nerves were obtained from postnatal day 7 (P7) male and female rats in accordance with the UK Animals (Scientific Procedures) Act 1986. Tissue was diced, digested in trypsin 0.05\% EDTA, then gently dissociated for $30 \mathrm{~min}$ at $37^{\circ} \mathrm{C}$. Dissociated tissue was sequentially immunopanned on Ran-2 (T1B-119; LGC Standards), antigalactocerebrosidase (GalC) (AB142; Millipore), and then O4 antibody plates (MAB1326; R\&D Systems) to select $\mathrm{GalC}^{-} \mathrm{O}^{+}{ }^{+} \mathrm{OPCs}$ (Zonouzi et al., 2011). Purified OPCs were transferred to poly-L-lysine-coated 24well tissue culture plates containing proliferation medium. All cells were cultured at $37^{\circ} \mathrm{C}, 5 \% \mathrm{CO}_{2}$, in DMEM (Invitrogen) containing Sato medium, as follows: human transferrin $(100 \mu \mathrm{g} / \mathrm{ml})$, bovine serum albumin $(100 \mu \mathrm{g} / \mathrm{ml})$, putrescine $(16 \mu \mathrm{g} / \mathrm{ml})$, progesterone $(60 \mathrm{ng} / \mathrm{ml})$, sodium selenite $(40 \mathrm{ng} / \mathrm{ml}), N$-acetyl-L-cysteine $(6.3 \mu \mathrm{g} / \mathrm{ml})$, bovine insulin $(5$ $\mu \mathrm{g} / \mathrm{ml}$ ) (Sigma), glutamine ( $2 \mathrm{~mm}$ ), sodium pyruvate (1 $\mathrm{mm}$ ), and penicillin-streptomycin (100 U each) (Sigma). Proliferation medium also contained OPC mitogens PDGF-AA and bFGF (both $10 \mathrm{ng} / \mathrm{ml}$ ) (R\&D Systems). OPCs were transfected with CNIH-3 and GFP DNA using $\mathrm{Ca}^{2+}$ phosphate, and recordings were made from labeled cells $24 \mathrm{~h}$ later.

Immunocytochemistry. OPC cultures on poly-L-lysine-coated coverslips were fixed with $4 \%$ PFA for $10 \mathrm{~min}$ at $25^{\circ} \mathrm{C}$ and washed with $1 \times$ PBS. Cells were then incubated with in $1 \times$ PBS containing $250 \mathrm{mg}$ of BSA (Sigma) and 10\% horse serum (Invitrogen) and (where stated) permeabilized with $0.5 \%$ Triton for $20 \mathrm{~min}$. Cells were labeled with primary antibodies for $1 \mathrm{~h}$ at $25^{\circ} \mathrm{C}$ : anti-O4 (mouse, MAB345, 1:100; Millipore) and anti-CNIH-2/3 antibody $(3.5 \mu \mathrm{g} / \mathrm{ml}$; a gift from Bernd Fakler, University of Freiburg, Freiburg, Germany). Secondary antibodies-goat anti-rabbit Alexa-568 (A-11011, 1:1000; Invitrogen) and goat antimouse Alexa-488 (A-21042, 1:1000; Invitrogen)—were applied for $1 \mathrm{~h}$ at $25^{\circ} \mathrm{C}$. Coverslips were mounted using anti-fade medium (Invitrogen). 
Statistical analysis. All group data were compared using a nonparametric Kruskal-Wallis rank-sum test followed by pairwise Wilcoxon ranksum tests with Holm's sequential Bonferroni correction for multiple comparisons ( $\mathrm{R}$, version 2.9.2; The R Foundation for Statistical Computing; http://www.R-project.org). Single comparisons were made using Wilcoxon rank-sum test. For all data, differences were considered significant at $p<0.05$.

\section{Results}

\section{Cornichons slow desensitization and deactivation of CP-} and CI-AMPARs

Recent studies of heterologously expressed recombinant AMPARs have shown that CNIH-2 and -3 can markedly slow receptor deactivation and desensitization (Schwenk et al., 2009; Kato et al., 2010a; Shi et al., 2010). We extended these observations by examining the influence of three $\mathrm{CNIH}$ family members (CNIH-1, -2, and -3) on multiple properties of both CI and CPAMPARs. First, using rapid application of glutamate $(10 \mathrm{~mm})$ onto outside-out membrane patches from tsA201 cells, we confirmed that both $\mathrm{CNIH}-2$ and -3 produced an approximately twofold slowing in the desensitization of homomeric GluA1 CPAMPARs (increased $\tau_{\mathrm{w} \text {, des }}$; Fig. $1 a, b$ ). This effect on desensitization was qualitatively similar to that seen with the TARP $\gamma$-2 (Fig. $1 b$ ), but for CNIH-2 the extent of slowing was significantly greater than that produced by $\gamma-2$ (Table 1$)$. CNIH-1, which has been shown not to interact with AMPARs (Schwenk et al., 2009), was without effect (Fig. 1b). In addition, we found that CNIH-2 and -3 slowed the deactivation (increased $\tau_{\mathrm{w} \text {, deact }}$ ) of homomeric GluA1 AMPARs (Table 1). CNIH-3 also slowed the deactivation and desensitization of GluA1/A2 heteromers (Fig. 1c, Table 1) and of homomeric GluA2(Q) receptors (Fig. 1d), with the latter the most markedly affected; $\tau_{\text {deact }}$ GluA2(Q) was increased more than 10 -fold by CNIH-3 (Table 1). This suggests subunit selective effects of the CNIHs. The slowing of desensitization by CNIH-2 and -3 was accompanied, in GluA2-containing receptors, by an increase in the steady state current (Table 1).

\section{Cornichons increase channel conductance of CP- but not CI-AMPARs}

To determine whether other functionally important AMPAR properties are regulated by cornichons, we examined their influence on channel gating, glutamate sensitivity, and calcium permeability. Although an effect of CNIH-2 on channel conductance of homomeric GluA1 receptors has recently been described (Shi et al., 2010), the effects of other cornichons have not been determined. We first estimated the single-channel conductance and peak open probability of agonist-bound channels $\left(P_{\mathrm{o} \text {, peak }}\right)$ using NSFA of macroscopic current responses. As expected, CNIH-2 increased the weighted mean single-channel conductance of homomeric GluA1 receptors ( 1.5-fold). A similar effect was seen with CNIH-3, and for both cornichons the effects were comparable to the increase seen with TARP $\gamma-2$ (Fig. $1 b$, Table 2). Again, $\mathrm{CNIH}-1$ was without effect. None of the coexpressed CNIH proteins altered $P_{\text {o, peak }}$ (Table 2 ).

The cornichon-induced change in channel conductance inferred from macroscopic currents was confirmed in separate recordings in which we analyzed directly resolved single-channel openings. Thus, when CNIH-3 was coexpressed with GluA1, steady state single-channel currents evoked by $10 \mathrm{~mm}$ glutamate $(-80 \mathrm{mV})$ (Fig. 1e) displayed markedly increased chord conductance (from $14.3 \pm 2.2$ to $22.3 \pm 1.3 \mathrm{pS} ; n=5$ and 7 , respectively; $p=0.030$ ), mean burst duration (from $5.2 \pm 1.0$ to $30.5 \pm 13.3$ $\mathrm{ms} ; p=0.030$ ), and mean open time (from $1.4 \pm 0.1$ to $5.7 \pm 2.0$
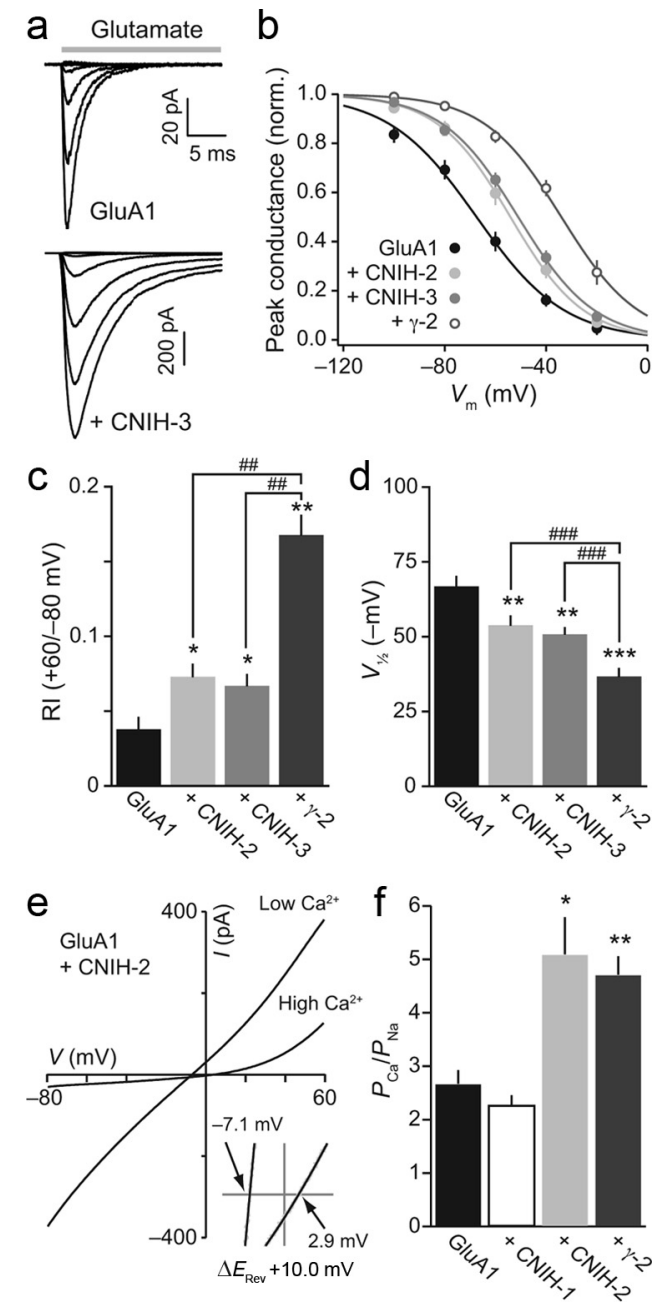

Figure 2. Cornichons affect polyamine block and $\mathrm{Ca}^{2+}$ permeability of CP-AMPARs. $\boldsymbol{a}$, Representative currents from outside-out patches taken from tsA201 cells expressing homomeric GluA1 receptors alone (top) or with CNIH-3 (bottom). Responses were evoked by rapid application of $10 \mathrm{~mm}$ glutamate (gray bar; $20 \mathrm{mV}$ steps from -100 to $+60 \mathrm{mV}$ ). $\boldsymbol{b}$, Plot of normalized conductance against voltage for GluA1 receptors expressed alone or with $\mathrm{CNIH}-2$, $\mathrm{CNIH}-3$, or $\gamma-2$. Symbols show mean values, and error bars denote SEM. Fitted lines are Boltzmann functions (see Materials and Methods). For each patch ( $n=6-24)$, data were fitted with a Boltzmann function and normalized to the peak of the individual fits before averaging. $c$, Pooled data showing the effect of $\mathrm{CNIH}$ and $\gamma-2$ on RI (see Table 2). $\boldsymbol{d}$, Pooled data showing the effect of CNIHs and $\gamma$-2 on individual patch $V_{1 / 2}$ values (see Table 2).e, $I-V$ relationships for homomeric GluA1 AMPARs expressed with $\mathrm{CNIH}-2$. Plots were obtained by ramping membrane potential from -80 to $+60 \mathrm{mV}(1.4 \mathrm{~s})$ in the presence of $1 \mathrm{~mm}$ glutamate plus $50 \mu \mathrm{m} \mathrm{CTZ.}\left[\mathrm{Ca}^{2+}\right]_{0}$ was changed from $1 \mathrm{~mm}\left(\right.$ low- $-\mathrm{Ca}^{2+}$ ) to $30 \mathrm{~mm}$ (high- $-\mathrm{Ca}^{2+}$ ). No spermine was added to the pipette solution. Inset, Reversal potentials in each solution. Solid lines crossing the voltage-axis are fits of third- or fourth-order polynomials to the raw data. $f$, Pooled data showing effects of CNIHs and $\boldsymbol{\gamma}$-2 on permeability of $\mathrm{Ca}^{2+}$ relative to $\mathrm{Na}^{+}\left(P_{\mathrm{Ca}} / P_{\mathrm{Na}}\right) . \boldsymbol{c}, \boldsymbol{d}, \boldsymbol{f}$, Bars show mean values, and error bars denote SEM. ${ }^{*} p<0.05,{ }^{* *} p<0.01,{ }^{* * *} p<0.0001$ versus control; \#\#p $<0.01$, $\# \# p<0.001$ versus $\gamma-2$

ms; $p=0.010$ ) (Fig. $1 f$ ). Effects on conductance were not restricted to homomeric GluA1 AMPARs. Both CNIH-2 and -3 also increased the conductance of homomeric GluA2(Q) receptors (Fig. $1 d$, Table 2). However, unlike TARP $\gamma$-2, neither CNIH-2 nor CNIH-3 affected the conductance of heteromeric GluA1/2 CI-AMPARs (Fig. 1c). This latter observation reveals a distinction between cornichons and TARPs in their regulation of channel properties and points to the possibility of a selective effect of cornichons on the conductance of CP-AMPARs. 
Cornichons are less effective than TARP $\boldsymbol{\gamma}-2$ in decreasing polyamine block of CP-AMPARs

TARPs decrease the block of CP-AMPARs by intracellular polyamines at positive and negative membrane potentials, reducing the characteristic inward rectification (Soto et al., 2007). We compared the polyamine block of CP-AMPARs (homomeric GluA1) when coassembled either with cornichon proteins or $\gamma-2$, by examining currents generated by fast application of glutamate to outside-out membrane patches $(-100 \mathrm{mV}$ to +60 $\mathrm{mV})$. Conductance-voltage $(G-V)$ plots were constructed from currents recorded in the negative voltage range (Fig. $2 a$ ) and fitted with Boltzmann functions (Fig. $2 b$ ). While both CNIH-2 and -3 caused clear rightward shifts in the fitted curves (depolarization in $V_{1 / 2}$ ), the change was significantly less marked than with $\gamma$-2 (Fig. $2 d$, Table 2). The rectification index $\left(\mathrm{RI}_{+60 /-}\right.$ 80; ratio of peak current at +60 and -80 $\mathrm{mV}$ ) increased in the presence of CNIH-2 and -3; however, this was significantly less that the change in RI seen with the coexpression of $\gamma-2$ (Fig. 2c, Table 2). Thus, using either measure to quantify relief of spermine block, CNIH-2 and -3 were less effective than $\gamma$-2. This result differs from that of Shi et al. (2010), who observed equivalent effects of TARP $\gamma$-2 and cornichons on polyamine block.

\section{Regulation of AMPAR calcium permeability}

To determine whether the CNIH-2induced change in spermine sensitivity was accompanied by a change in the relative permeability of $\mathrm{Ca}^{2+}\left(P_{\mathrm{Ca}} / P_{\mathrm{Na}}\right)$, we compared the reversal potential of glutamate-evoked currents in solutions containing 1 or $30 \mathrm{mM} \mathrm{Ca}^{2+}$ (low- $\mathrm{Ca}^{2+}$ or high- $\mathrm{Ca}^{2+}$ ). Switching from low- to high- $\mathrm{Ca}^{2+}$ shifted the reversal potentials for homomeric GluA1 receptors toward more negative values. By contrast, when GluA1 receptors were coexpressed with $\mathrm{CNIH}-2$ or $\gamma-2$, the same manipulation shifted the reversal potential to positive membrane potential values (Fig. $2 e, f$ ). From these $E_{\text {rev }}$ shifts, we calculated that $P_{\mathrm{Ca}} / P_{\mathrm{Na}}$ increased from $2.7 \pm 0.3$ with GluA1 alone $(n=9)$ to $5.1 \pm 0.7$ in the presence of CNIH-2 $(n=9, p=$ $0.049)$ and to $4.7 \pm 0.4$ in the presence of $\gamma-2(n=8, p=0.0017)$ (Fig. $3 b$ ). As expected, we saw no significant change in $P_{\mathrm{Ca}} / P_{\mathrm{Na}}$ when $\mathrm{CNIH}-1$ was coexpressed with GluAl $(2.3 \pm 0.2, n=9, p=0.57)$.

\section{CNIH-2 enhances glutamate potency}

We next asked whether CNIH-2, like $\gamma$-2 (Yamazaki et al., 2004; Priel et al., 2005; Tomita et al., 2005b; Kato and Bredt, 2007; Kott et al., 2007), modified glutamate potency, a measure that reflects both receptor affinity and gating. Using rapid application of glutamate $(0.03-10 \mathrm{~mm})$ onto excised patches, we constructed concentration-response curves for the peak current (Fig. $3 a, b$ ). For homomeric GluA1 receptors, the glutamate $\mathrm{EC}_{50 \text {, peak }}$ de-

\section{Glutamate}
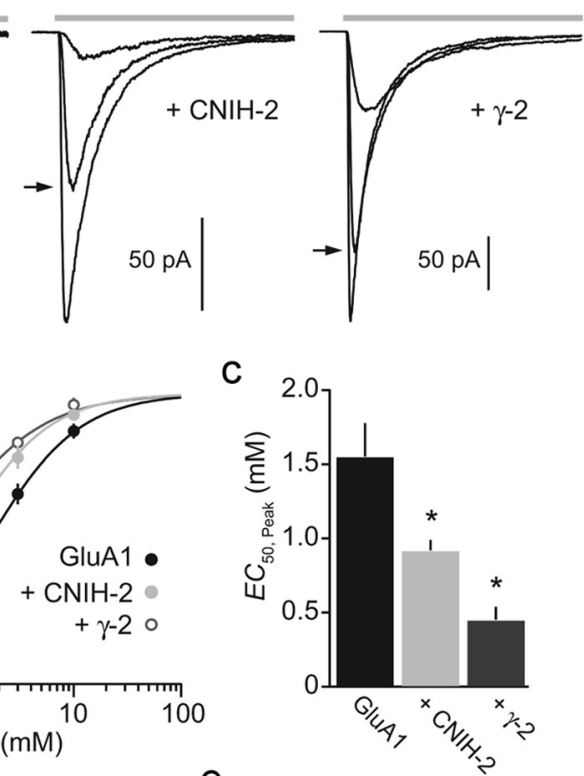

e

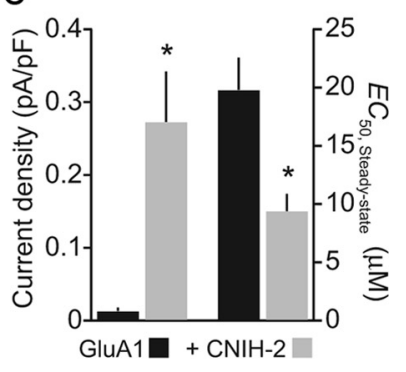

Glutamate $(\mathrm{mM})$
GluA1
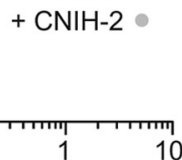

)
(1)

Figure 3. CNIH-2 increases glutamate potency at GluA1 receptors. $\boldsymbol{a}$, Representative GluA1 responses to rapid glutamate applications (0.1, 1, and $10 \mathrm{~mm}$; horizontal gray bars) for GluA1 expressed alone or with $\mathrm{CNIH}-2$ or $\gamma$-2. Arrows indicate the peak of Materials and Methods) and then normalized to the peak of the individual fit. Averages (plus SEM) of these normalized data are

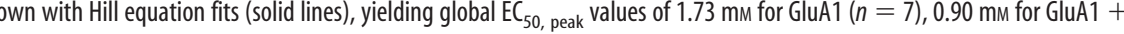

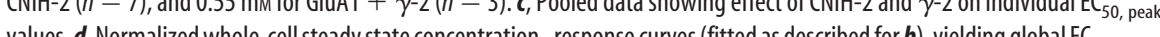

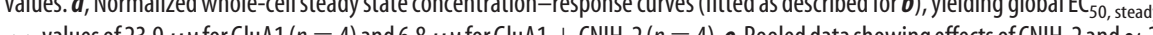
state values of $23.9 \mu \mathrm{m}$ for GluA1 $(n=4)$ and $6.8 \mu \mathrm{m}$ for GluA1 + CNIH-2 $(n=4) . e$, Pooled data showing effects of CNIH-2 and $\gamma$ - 2 on individual $\mathrm{EC}_{50 \text {, steady state }}$ and current density (response normalized to input capacitance) values. $\boldsymbol{c}, \boldsymbol{e}$, Bars show mean values, and error bars denote SEM. ${ }^{*} p<0.05$. creased from $1.55 \pm 0.22 \mathrm{~mm}$ to $0.92 \pm 0.07 \mathrm{~mm}$ in the presence of CNIH-2 (both $n=7, p=0.033$ ) and to $0.45 \pm 0.09 \mathrm{~mm}$ with $\gamma-2(n=3, p=0.033)$ (Fig. $3 c)$. The measurement of peak responses to rapid glutamate application provides information most relevant to direct synaptic responses. AMPARs in neurons or glia that are not in close apposition to release sites may be exposed to glutamate concentration transients of relatively slow time course. Thus, during transmitter spillover, the glutamate transient that activates extrasynaptic AMPARs reaches a relatively low concentration that lasts for many milliseconds (Bergles et al., 1999; Szapiro and Barbour, 2007). Additionally, activation of AMPARs within the endoplasmic reticulum, where glutamate activates gating movements that are suggested to be critical for AMPAR biogenesis (Penn et al., 2008; Coleman et al., 2009), may well occur under near-equilibrium conditions. We therefore examined whole-cell responses to bath-applied glutamate (0.001-1 $\mathrm{mM}$ ) to obtain steady state responses (Fig. $3 d, e$ ). CNIH-2 lowered $\mathrm{EC}_{50, \text { steady state }}$ from $19.8 \pm 2.7 \mu \mathrm{M}(n=4)$ to $9.4 \pm 1.4 \mu \mathrm{M}(n=$ $4, p=0.029$ ) and greatly increased current density (Fig. 3e). Thus, CNIH-2 produced statistically significant, albeit modest, 
a

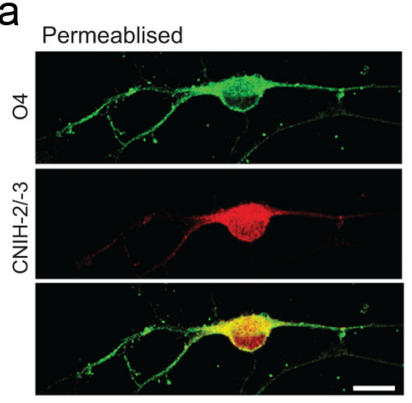

b Non-permeabilised

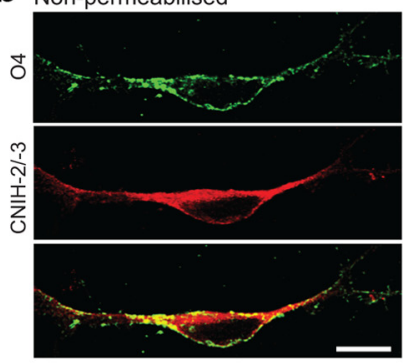

C

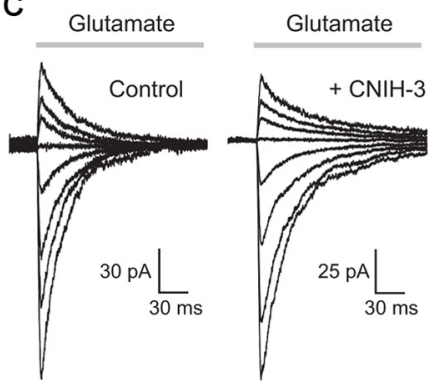

d
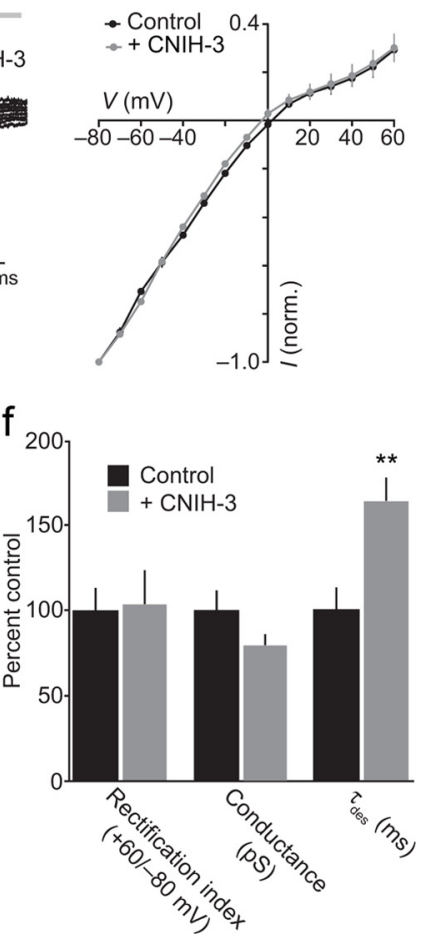

Figure 4. CNIH presence and overexpression in cultured glial cells. $\boldsymbol{a}$, Representative images of a permeabilized OPC identified by the specific marker 04 showing labeling of the soma and processes with an antibody to $\mathrm{CNIH}-2 / 3 . \boldsymbol{b}$, Representative images of a nonpermeabilized OPC showing surface labeling with an antibody to CNIH-2/3. Scale bars, $10 \mu \mathrm{m}$. C, Representative responses evoked by rapid application of $10 \mathrm{~mm}$ glutamate (gray bar; $10 \mathrm{mV}$ steps from -80 to $+60 \mathrm{mV}$ ) to outside-out patches from a control OPC (left) and one transfected with CNIH-3 (right). $\boldsymbol{d}$, I-V relationships from pooled data of the type shown in $(n=3$ patches each). Symbols show mean and error bars denote SEM. $e$, Currents elicited by $100 \mathrm{~ms}$ application of glutamate to an outside-out patch from a control OPC and one transfected with $\mathrm{CNIH}-3(-80 \mathrm{mV})$. Note the slower desensitization. $\boldsymbol{f}$, Pooled data showing lack of effect of CNIH-3 overexpression on RI $(n=3$ cells each for control and $\mathrm{CNIH}-3)$ and weighted mean single-channel conductance $(n=7$ and 8 ) and the significant slowing of desensitization ( $n=9$ and 11). Bars show mean values, and error bars denote SEM. ${ }^{* *} p<0.01$ versus control.

enhancement of CP-AMPAR activation, in response to both rapid glutamate transients and sustained glutamate application.

Although we have shown, with heterologous expression, that cornichons can influence key aspects of AMPAR function, including glutamate potency, channel kinetics, channel conductance, polyamine block, and calcium permeability, a question remains as to the physiological relevance of such changes. For hippocampal neurons at least, there is evidence for the incorporation of cornichons within synaptic AMPARs, either alone (Schwenk et al., 2009) or in combination with TARP $\gamma$-8 (Kato et al., 2010b; Gill et al., 2011). But there is no general consensus on this point. Thus, Shi et al. (2010) reported that neuronal overexpression of epitope-tagged CNIH-2 led to high protein density in the Golgi apparatus, but not at the cell surface, leading them to conclude that cornichons act as endoplasmic reticulum (ER) chaperones (Brockie and Maricq, 2010; Shi et al., 2010). While the study of Schwenk et al. (2009) identified CNIH-2/3 immunoreactivity in various glial cells (including Bergmann glia and hippocampal astrocytes), the issue of whether cornichon association modifies surface AMPARs in glia has not been addressed. We chose to examine this question in OPCs. These immature glia, which give rise to oligodendrocytes responsible for axonal myelination, express both CP- and CI-AMPARs (De Biase et al., 2010) and can be prepared from optic nerve as pure cultures (Shi et al., 1998).

\section{CNIHs are present at the surface of OPCs}

We first examined the labeling of OPCs with an anti-CNIH antibody, used previously to identify cornichon expression in native tissue. This antibody recognizes both CNIH-2 and -3 (Schwenk et al., 2009) and, in our hands, labeled tsA201 cells transfected with CNIH-2 but not untransfected cells (data not shown). OPCs in culture were identified with an antibody to $\mathrm{O} 4$, a specific marker protein (Fig. 4). When permeabilized, OPCs displayed a high level of labeling with the CNIH-2/3 antibody, in both the soma and fine processes (Fig. 4a). Nonpermeabilized OPCs also exhibited intense surface labeling for $\mathrm{CNIH}-2 / 3$, consistent with the presence of cornichon proteins in the cell membrane (Fig. $4 b$ ).

\section{Functional properties of OPC AMPARs are influenced by CNIHs}

To determine whether cornichons in the surface membrane of OPCs were likely to be associated with AMPARs that might be influencing their functional properties, we examined the kinetic behavior, rectification, and channel conductance of AMPARs in control cells and in cells overexpressing CNIH-3. Untreated OPCs exhibited $I-V$ relationships with moderate inward rectification (Fig. $4 c, d$ ), consistent with the presence of a mixed population of CP- and CI-AMPARs. The relatively high channel conductance, estimated from NSFA ( $35.4 \pm 4.2 \mathrm{pS}, n=7)$, suggested that in these untreated OPCs, AMPARs are normally associated with auxiliary subunits. Overexpression of CNIH-3 did not significantly alter the rectification of AMPAR currents $\left(\mathrm{RI}_{+60 /-80}\right.$ control $0.29 \pm 0.04 ;+\mathrm{CNIH}-30.30 \pm 0.06 ; n=3$ each; $p=1.0)$ or channel conductance $(+\mathrm{CNIH}-328.3 \pm 2.2 \mathrm{pS}$; $n=8 ; p=0.093$ ), suggesting that the relative proportions of CPand CI-AMPAR subunits were not greatly affected. However, the weighted mean time constant of desensitization $\left(\tau_{\text {des }}\right)$ was in- 

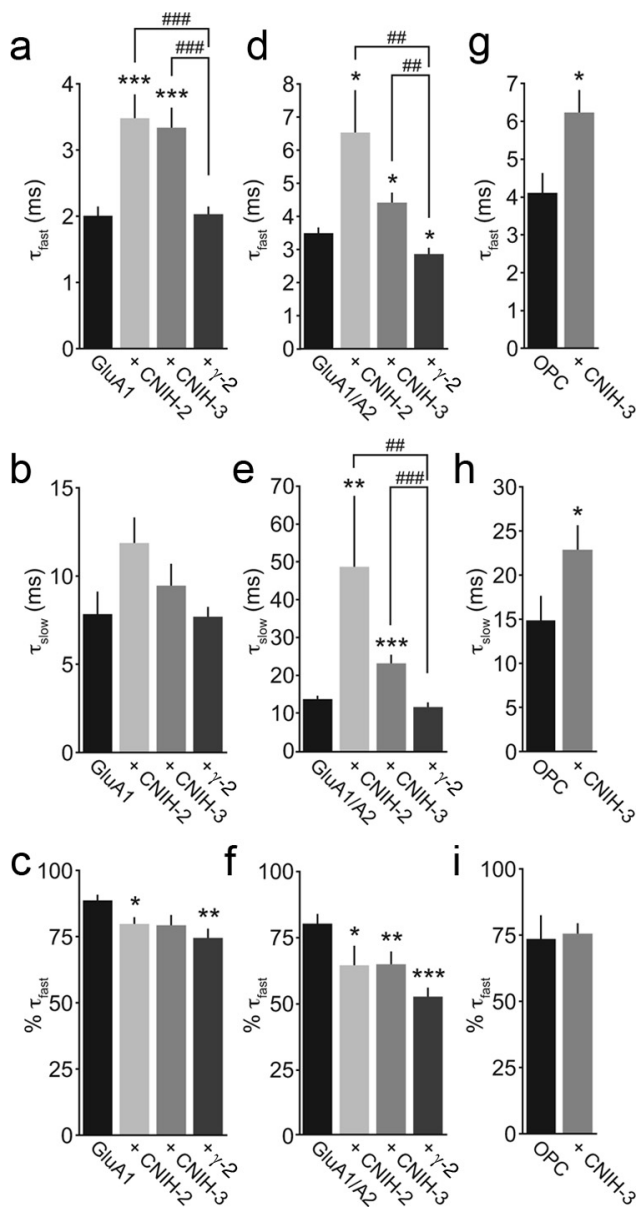

Figure 5. Comparison of CNIH effects on desensitization kinetics of recombinant AMPARs and those in OPCs. $\boldsymbol{a}-\boldsymbol{c}$, Pooled data showing the effects of $\mathrm{CNHH}-2$, $\mathrm{CNIH}-3$, and $\gamma$-2 on the time constant of the fast component of desensitization $\left(\tau_{\text {fast }}\right)$, the time constant of the slow component of desensitization $\left(\tau_{\text {slow }}\right)$, and the proportion of desensitization mediated by the fast component $\left(\% \tau_{\text {fast }}\right)$. In all cases, bars show mean values and error bars denote SEM. $\boldsymbol{d}-\boldsymbol{f}$, Corresponding data for heteromeric GluA1/A2 receptors. $\boldsymbol{a}-\boldsymbol{f},{ }^{*} p<0.05,{ }^{* *} p<0.01,{ }^{* * *} p<$ 0.0001 versus control; \#\#p $<0.01$, \#\#\# $p<0.001$ versus $\gamma-2 . \boldsymbol{g}-\boldsymbol{i}$, Corresponding data for control OPCs and those in which CNIH-3 was overexpressed. ${ }^{*} p<0.05$.

creased from $6.2 \pm 0.8 \mathrm{~ms}$ to $10.0 \pm 0.8 \mathrm{~ms}(n=9$ and 11 ; $p=0.0034$ ) (Fig. $4 g$ ). The effects of CNIH-3 on rectification, weighted-mean single-channel conductance, and $\tau_{\mathrm{des}}$ are compared in Figure $4 h$.

We next compared the effects of CNIH-3 on the desensitization of AMPARs in OPCs with the effects of CNIH-2, CNIH-3, and TARP $\gamma$-2 on the desensitization of recombinant AMPARs. Specifically, we examined the kinetics and relative proportions of the fast and slow components of desensitization (Fig. 5). For homomeric GluA1 CP-AMPARs, CNIH-2 and -3 preferentially slowed the fast component $\left(\tau_{\text {fast }}\right.$; Fig. $\left.5 a-c\right)$. For GluA1/A2 CIAMPARs, CNIH-2 and -3 slowed both the fast and the slow components $\left(\tau_{\text {fast }}\right.$ and $\tau_{\text {slow }}$; Fig. $\left.5 d-f\right)$. This contrasts with the effect of TARP $\gamma$-2, which for both CP- and CI-AMPARs primarily decreased the relative proportion of the fast component of desensitization (Fig. $5 a-f$ ). In OPCs, the overexpression of CNIH-3 slowed $\tau_{\text {fast }}$ and $\tau_{\text {slow }}$ to similar extents, without changing their relative contribution (Fig. $5 g-i$ ). It is of note that in untreated OPCs, both components of desensitization appeared slower than would be expected for a mixed population of CP- and CIAMPARs associated solely with TARP $\gamma-2$.
In an attempt to identify the potential contribution of cornichons to AMPARs in OPCs, we examined the relative amplitude of AMPAR-mediated currents elicited by kainate $\left(I_{\mathrm{KA}}\right)$ and glutamate $\left(I_{\mathrm{Glu}}\right)$ ( $1 \mathrm{~mm}$ each plus $100 \mu \mathrm{M}$ CTZ). Previous studies have shown that AMPAR auxiliary subunits differentially increase the efficacy of the partial agonist kainate, thereby altering, to varying extents, the $I_{\mathrm{KA}} / I_{\mathrm{Glu}}$ ratio (Tomita et al., 2005a; Turetsky et al., 2005; Shi et al., 2010). For GluA1 receptors, the effect of CNIH-3 was modest, with an approximately four-fold shift in the ratio (from $0.026 \pm 0.004$ to $0.10 \pm 0.03 ; n=4$ and 5 , respectively). This effect of $\mathrm{CNIH}-3$ was significantly less $(p=$ 0.029 ) than the 16 -fold shift produced by $\gamma$-2 (to $0.43 \pm 0.03, n=$ $7)$. With the coexpression of both $\mathrm{CNIH}-3$ and $\gamma$-2, the $I_{\mathrm{KA}} / I_{\mathrm{Glu}}$ ratio was similar to that with $\gamma$-2 alone $(0.42 \pm 0.08, n=5 ; p=$ $0.52)$. For AMPARs in untreated OPCs, the $I_{\mathrm{KA}} / I_{\mathrm{Glu}}$ ratio was $0.42 \pm 0.04(n=6)$, similar to that of recombinant receptors in the presence of TARP or both TARP and cornichon.

Next, we examined the degree to which CTZ $(100 \mu \mathrm{M})$ potentiated currents evoked by kainate $(1 \mathrm{mM},-60 \mathrm{mV})$. With homomeric GluA1 receptors, $I_{\mathrm{KA}}$ was increased $\sim 12$-fold by CTZ (to $1294 \pm 260 \%$ of control, $n=5)$. GluA1 receptors coexpressed with CNIH-3 were similarly potentiated $(1234 \pm 385 \%, n=3$; $p=1.00)$. By contrast, following coexpression with TARP $\gamma-2$ or with both $\gamma$-2 and CNIH-3, CTZ produced a much lesser effect (196 \pm 18 and $326 \pm 42 \%$ of control, respectively; $n=5$ and 4 ; $p=0.037$ and 0.040 ). This result is consistent with recent findings showing that CTZ potentiation of $I_{\mathrm{KA}}$ is reduced for heteromeric GluA1/2/CNIH-2 receptors when coexpressed with TARP $\gamma-8$ (Kato et al., 2010b). In control OPCs, the CTZ potentiation $(458 \pm 55 \%, n=7)$ was significantly greater than that seen with GluA1 plus $\gamma$-2 alone $(p=0.047)$ and closest to that seen with GluA1/ $\gamma$-2/CNIH-3 coexpression $(p=0.47)$, providing suggestive evidence that the receptors in OPCs may be associated with both TARP and cornichon.

Finally, as we have recently shown that the prevalence of CPAMPARs in OPCs can be dynamically regulated in a TARPdependent manner by the activation of Group 1 mGluRs and purinergic receptors (Zonouzi et al., 2011), we asked whether such changes in AMPAR expression might be accompanied by changes in $\mathrm{CNIH}$ association. After treatment of OPCs with ATP ( $1 \mathrm{~mm}$ for $10 \mathrm{~min}$ at $37^{\circ} \mathrm{C}$ ) (Zonouzi et al., 2011), which promotes a switch toward CI-AMPARs, the CTZ potentiation of $I_{\mathrm{KA}}(396 \pm$ $42 \%, n=5)$ remained similar to GluA1/ $\gamma-2 / \mathrm{CNIH}-3(p=0.66)$ and different from GluA1 plus $\gamma-2$ alone $(p=0.049)$.

\section{Discussion}

CNIHs and TARPs similarly modify AMPAR gating but have different effects on pharmacology

In this study, we have recorded macroscopic and single-channel currents to examine the effects of CNIHs on the properties of recombinant and native AMPARs, concentrating on the behavior of CP-AMPARs. Our data indicate that CNIH-2 and -3 slow the kinetics of CP-AMPARs, increase their glutamate sensitivity, increase their single-channel conductance, and increase calciumpermeability while reducing their block by intracellular polyamines. Thus, CNIH association would be expected to enhance the activation of and calcium flux through CP-AMPARs. These effects of CNIHs are largely comparable to those described previously for TARPs. However, more detailed kinetic analysis suggests that the TARPs and CNIHs differ in the means by which they slow desensitization: CNIHs decrease the rate of both the slow and the fast components, while $\gamma-2$ increases the proportion of the slower component. 
A clear difference between CNIHs and TARPs is seen in their effects on kainate efficacy, which are greater for the TARPs than the CNIHs. Our data demonstrate that additional expression of CNIH-3 does not change the $I_{\mathrm{KA}} / I_{\mathrm{Glu}}$ ratio of GluAl $/ \gamma$ - 2 assemblies but does increase the CTZ sensitivity of $I_{\mathrm{KA}}$, indicating that CNIHs can interact with and modify the AMPAR/TARP complex. These effects are similar to those seen with coexpression of CNIH-2 with GluA1 and $\gamma-8$ (Kato et al., 2010b) or with a GluA1$\gamma-8$ chimera (Shi et al., 2010). Thus, detailed kinetic analysis and examination of kainate pharmacology can be used to evaluate the TARP/CNIH content of native receptors.

\section{CNIHs are expressed at the surface of glial cells}

The functional importance of CNIHs in neurons has been the subject of controversy. Initial suggestions that CNIHs and TARPs were not found in the same receptor complexes (Schwenk et al., 2009) and failed to traffic to the neuronal surface (Shi et al., 2010) led to the hypothesis that CNIHs were simply responsible for biosynthetic trafficking of AMPARs intracellularly. This would represent conservation of the role performed by CNIH homologs in Drosophila and yeast (Cni and Erv14p), which participate in protein maturation by facilitating the export of nascent protein from the ER to the Golgi apparatus in CopII vesicles (Bokel et al., 2006; Castillon et al., 2009). By contrast, data from Kato et al. (2010b) suggested that CNIH-2 could functionally interact with AMPARs containing TARP $\gamma-8$, both in the hippocampus and in cerebellar granule neurons from stargazer mice transfected with $\gamma-8$. Recent evidence suggests that in hippocampal and cerebellar neurons the presence of CNIH-2 can alter AMPAR/TARP stoichiometry, although it associates with surface AMPARs only in the presence of specific TARPs (Gill et al., 2011). Thus, it now seems clear that CNIHs can interact with neuronal AMPARs in the presence of TARPs to modulate receptor function.

Although CNIH2/3 isoforms have previously been identified in Bergmann glia by immunocytochemistry (Schwenk et al., 2009), we have demonstrated, for the first time, that they have functional effects on AMPARs in glial cells. We have shown that $\mathrm{CNIH}-2 / 3$ immunoreactivity is present at the surface of OPCs and that, when overexpressed, $\mathrm{CNIH}-3$ can modulate the kinetic and pharmacological properties of AMPARs. While some of the pharmacological aspects of OPC AMPAR responses could be attributed to CNIH coassembly, this does not conclusively demonstrate that CNIHs are elements of AMPAR signaling in OPCs. Nevertheless, taken at face value, our data suggest that surface AMPARs in OPCs may not normally be saturated with CNIHs. The incorporation of CNIHs in AMPAR subunit assemblies may occur at the expense of TARP components (Gill et al., 2011, 2012) or may simply lead to receptors with additional auxiliary subunits. OPCs express several TARP isoforms (Cahoy et al., 2008), and we have shown recently that $\gamma-2$ is important for both constitutive trafficking and mGluR-mediated insertion of GluA2lacking CP-AMPARs in these cells (Zonouzi et al., 2011). The additional presence of mRNA for $\gamma-3, \gamma-4$, and $\gamma-5$ (Zonouzi et al., 2011) and CNIH-2/3 protein (Fig. 4), together with a mixed population of CP- and CI-AMPARs (Fig. 4), suggests the potential for significant AMPAR heterogeneity in OPCs. The $I_{\mathrm{KA}} / I_{\mathrm{Glu}}$ ratio we obtained in OPCs is consistent with the presence of Type I TARPs (either with or without CNIHs). However, the presence of receptors containing $\mathrm{CNIH}-2 / 3$ is suggested by the degree of potentiation of $I_{\mathrm{KA}}$ by CTZ, which is larger than would be expected for AMPARs associated with TARP alone. Furthermore, both the slow and fast time constants of AMPAR desensitization in OPCs are slower than those expected for $\mathrm{CNIH}$-free receptors
(Fig. 5). Thus, our electrophysiological data are in line with the emerging view that TARPs and CNIHs not only interact with the same AMPARs at the cell surface but that their precise stoichiometries dictate the properties of AMPAR populations (Gill et al., 2011, 2012).

\section{CNIHs and OPC AMPAR plasticity}

In OPCs, the prevalence of CP-AMPARs can be dynamically regulated, in a TARP-dependent manner, by activation of metabotropic glutamate and purinergic receptors (Zonouzi et al., 2011). In the present study, we found that following exposure to ATP (which induces a switch to CI-AMPARs) the kainate pharmacology of the receptors was unchanged, suggesting the dual presence of TARPs and CNIHs, both before and after plasticity. It is tempting to speculate that synaptic plasticity in neurons expressing CNIHs, such as hippocampal CA1 neurons, may also involve the trafficking of CNIH-containing receptors. The exact mechanisms underlying AMPAR plasticity in OPCs are not yet fully understood, but it is likely that new cell surface receptors originate from intracellular pools or from the extrasynaptic membrane (Shi et al., 1999; Bats et al., 2007). While modification of TARPs by phosphorylation can facilitate AMPAR cell surface trafficking and lateral diffusion in the membrane (Tomita et al., 2005a; Bats et al., 2007; Opazo et al., 2010; Sumioka et al., 2010) a direct role of CNIHs in plasticity has not been described. It is possible that $\mathrm{CNIHs}$ are passive in this regard, with post-Golgi receptor trafficking being dictated by the TARPs. However, it is also possible that CNIHs play a specific role in plasticity, either by directly dictating receptor trafficking or by influencing this indirectly by modifying TARP stoichiometry. Further studies are required to resolve these issues. During development, OPCs receive glutamatergic inputs from neurons (Bergles et al., 2000), which influence oligodendrocyte migration (Gudz et al., 2006). The means by which AMPARs in OPCs are trafficked and targeted to these "synaptic" sites is unresolved, but CNIH-2/3, by enhancing steady state currents, assisting receptor biogenesis, or facilitating AMPAR plastic changes, may influence the processes responsible for establishing such connections.

\section{References}

Bats C, Groc L, Choquet D (2007) The interaction between stargazin and PSD-95 regulates AMPA receptor surface trafficking. Neuron 5:719-734.

Bergles DE, Diamond JS, Jahr CE (1999) Clearance of glutamate inside the synapse and beyond. Curr Opin Neurobiol 9:293-298.

Bergles DE, Roberts JD, Somogyi P, Jahr CE (2000) Glutamatergic synapses on oligodendrocyte precursor cells in the hippocampus. Nature 405:187-191.

Bökel C, Dass S, Wilsch-Bräuninger M, Roth S (2006) Drosophila cornichon acts as cargo receptor for ER export of the TGFalpha-like growth factor Gurken. Development 133:459-470.

Bowie D, Mayer ML (1995) Inward rectification of both AMPA and kainate subtype glutamate receptors generated by polyamine-mediated ion channel block. Neuron 15:453-462.

Brockie PJ, Maricq AV (2010) In a pickle: is cornichon just relish or part of the main dish? Neuron 68:1017-1019.

Cahoy JD, Emery B, Kaushal A, Foo LC, Zamanian JL, Christopherson KS, Xing Y, Lubischer JL, Krieg PA, Krupenko SA, Thompson WJ, Barres BA (2008) A transcriptome database for astrocytes, neurons, and oligodendrocytes: a new resource for understanding brain development and function. J Neurosci 28:264-278.

Castillon GA, Watanabe R, Taylor M, Schwabe TM, Riezman H (2009) Concentration of GPI-anchored proteins upon ER exit in yeast. Traffic 10:186-200.

Cho CH, St-Gelais F, Zhang W, Tomita S, Howe JR (2007) Two families of TARP isoforms that have distinct effects on the kinetic properties of AMPA receptors and synaptic currents. Neuron 55:890-904. 
Coleman SK, Möykkynen T, Jouppila A, Koskelainen S, Rivera C, Korpi ER, Keinänen K (2009) Agonist occupancy is essential for forward trafficking of AMPA receptors. J Neurosci 29:303-312.

De Biase LM, Nishiyama A, Bergles DE (2010) Excitability and synaptic communication within the oligodendrocyte lineage. J Neurosci 30: 3600-3611.

Fukaya M, Yamazaki M, Sakimura K, Watanabe M (2005) Spatial diversity in gene expression for VDCCgamma subunit family in developing and adult mouse brains. Neurosci Res 53:376-383.

Geiger JR, Melcher T, Koh DS, Sakmann B, Seeburg PH, Jonas P, Monyer H (1995) Relative abundance of subunit mRNAs determines gating and $\mathrm{Ca}^{2+}$ permeability of AMPA receptors in principal neurons and interneurons in rat CNS. Neuron 15:193-204.

Gill MB, Kato AS, Roberts MF, Yu H, Wang H, Tomita S, Bredt DS (2011) Cornichon-2 modulates AMPA receptor-transmembrane AMPA receptor regulatory protein assembly to dictate gating and pharmacology. J Neurosci 31:6928-6938.

Gill MB, Kato AS, Wang H, Bredt DS (2012) AMPA receptor modulation by cornichon-2 dictated by transmembrane AMPA receptor regulatory protein isoform. Eur J Neurosci 35:182-194.

Gudz TI, Komuro H, Macklin WB (2006) Glutamate stimulates oligodendrocyte progenitor migration mediated via an $\alpha \mathrm{v}$ integrin/myelin proteolipid protein complex. J Neurosci 26:2458-2466.

Jackson AC, Nicoll RA (2009) Neuroscience: AMPA receptors get 'pickled'. Nature 458:585-586.

Jackson AC, Nicoll RA (2011) The expanding social network of ionotropic glutamate receptors: TARPs and other transmembrane auxiliary subunits. Neuron 70:178-199.

Kamboj SK, Swanson GT, Cull-Candy SG (1995) Intracellular spermine confers rectification on rat calcium-permeable AMPA and kainate receptors. J Physiol 486:297-303.

Kato AS, Bredt DS (2007) Pharmacological regulation of ion channels by auxiliary subunits. Curr Opin Drug Discov Devel 10:565-572.

Kato AS, Siuda ER, Nisenbaum ES, Bredt DS (2008) AMPA receptor subunit-specific regulation by a distinct family of type II TARPs. Neuron 59:986-996.

Kato AS, Gill MB, Yu H, Nisenbaum ES, Bredt DS (2010a) TARPs differentially decorate AMPA receptors to specify neuropharmacology. Trends Neurosci 33:241-248.

Kato AS, Gill MB, Ho MT, Yu H, Tu Y, Siuda ER, Wang H, Qian YW, Nisenbaum ES, Tomita S, Bredt DS (2010b) Hippocampal AMPA receptor gating controlled by both TARP and cornichon proteins. Neuron 68:1082-1096.

Koh DS, Burnashev N, Jonas P (1995) Block of native $\mathrm{Ca}^{2+}$-permeable AMPA receptors in rat brain by intracellular polyamines generates double rectification. J Physiol 486:305-312.

Kott S, Werner M, Körber C, Hollmann M (2007) Electrophysiological properties of AMPA receptors are differentially modulated depending on the associated member of the TARP family. J Neurosci 27:3780-3789.

Milstein AD, Zhou W, Karimzadegan S, Bredt DS, Nicoll RA (2007) TARP subtypes differentially and dose-dependently control synaptic AMPA receptor gating. Neuron 55:905-918.

Opazo P, Labrecque S, Tigaret CM, Frouin A, Wiseman PW, De Koninck P, Choquet D (2010) CaMKII triggers the diffusional trapping of surface AMPARs through phosphorylation of stargazin. Neuron 67:239-252.

Penn AC, Williams SR, Greger IH (2008) Gating motions underlie AMPA receptor secretion from the endoplasmic reticulum. EMBO J 27:30563068 .

Priel A, Kolleker A, Ayalon G, Gillor M, Osten P, Stern-Bach Y (2005) Stargazin reduces desensitization and slows deactivation of the AMPA-type glutamate receptors. J Neurosci 25:2682-2686.

Schwenk J, Harmel N, Zolles G, Bildl W, Kulik A, Heimrich B, Chisaka O, Jonas P, Schulte U, Fakler B, Klöcker N (2009) Functional proteomics identify cornichon proteins as auxiliary subunits of AMPA receptors. Science 323:1313-1319.

Shi J, Marinovich A, Barres BA (1998) Purification and characterization of adult oligodendrocyte precursor cells from the rat optic nerve. J Neurosci 18:4627-4636.

Shi SH, Hayashi Y, Petralia RS, Zaman SH, Wenthold RJ, Svoboda K, Malinow R (1999) Rapid spine delivery and redistribution of AMPA receptors after synaptic NMDA receptor activation. Science 284:1811-1816.

Shi Y, Suh YH, Milstein AD, Isozaki K, Schmid SM, Roche KW, Nicoll RA (2010) Functional comparison of the effects of TARPs and cornichons on AMPA receptor trafficking and gating. Proc Natl Acad Sci U S A 107:16315-16319.

Soto D, Coombs ID, Kelly L, Farrant M, Cull-Candy SG (2007) Stargazin attenuates intracellular polyamine block of calcium-permeable AMPA receptors. Nat Neurosci 10:1260-1267.

Soto D, Coombs ID, Renzi M, Zonouzi M, Farrant M, Cull-Candy SG (2009) Selective regulation of long-form calcium-permeable AMPA receptors by an atypical TARP, gamma-5. Nat Neurosci 12:277-285.

Sumioka A, Yan D, Tomita S (2010) TARP phosphorylation regulates synaptic AMPA receptors through lipid bilayers. Neuron 66:755-767.

Swanson GT, Kamboj SK, Cull-Candy SG (1997) Single-channel properties of recombinant AMPA receptors depend on RNA editing, splice variation, and subunit composition. J Neurosci 17:58-69.

Szapiro G, Barbour B (2007) Multiple climbing fibers signal to molecular layer interneurons exclusively via glutamate spillover. Nat Neurosci 10:735-742.

Tigaret C, Choquet D (2009) Neuroscience: more AMPAR garnish. Science 323:1295-1296.

Tomita S, Chen L, Kawasaki Y, Petralia RS, Wenthold RJ, Nicoll RA, Bredt DS (2003) Functional studies and distribution define a family of transmembrane AMPA receptor regulatory proteins. J Cell Biol 161:805-816.

Tomita S, Stein V, Stocker TJ, Nicoll RA, Bredt DS (2005a) Bidirectional synaptic plasticity regulated by phosphorylation of stargazin-like TARPs. Neuron 45:269-277.

Tomita S, Adesnik H, Sekiguchi M, Zhang W, Wada K, Howe JR, Nicoll RA, Bredt DS (2005b) Stargazin modulates AMPA receptor gating and trafficking by distinct domains. Nature 435:1052-1058.

Traynelis SF, Wollmuth LP, McBain CJ, Menniti FS, Vance KM, Ogden KK, Hansen KB, Yuan H, Myers SJ, Dingledine R (2010) Glutamate receptor ion channels: structure, regulation, and function. Pharmacol Rev 62:405-496.

Turetsky D, Garringer E, Patneau DK (2005) Stargazin modulates native AMPA receptor functional properties by two distinct mechanisms. J Neurosci 25:7438-7448.

Yamazaki M, Ohno-Shosaku T, Fukaya M, Kano M, Watanabe M, Sakimura K (2004) A novel action of stargazin as an enhancer of AMPA receptor activity. Neurosci Res 50:369-374.

Zonouzi M, Renzi M, Farrant M, Cull-Candy SG (2011) Bidirectional plasticity of calcium-permeable AMPA receptors in oligodendrocyte lineage cells. Nat Neurosci 14:1430-1438. 